\title{
How Patents Influence Market Value of Industrial Enterprises' Assets?
}

\author{
Dmitry Dementev \\ Candidate of Economic Sciences, Associate Professor, Department of Audit, Accounting and Finance, Novosibirsk State \\ Technical University, Novosibirsk, Russia,
} dmvit68@yandex.ru, ORCID

\section{Abstract}

Scientists and engineers are continuously patenting innovative ideas such as inventions, industrial designs, and utility models. It is therefore relevant to pose the question of the influence of intellectual property in the field of innovative technologies on the market value of the assets of industrial enterprises.

We analyse the dependence of the results of intellectual activity in the field of advanced technologies on the capitalization of innovative industrial production after the adoption of the developed technologies.

We consider patent landscapes, analyse research publications, and study the dependence of financial indicators on the results of intellectual activity at enterprises producing computers, optics and electronic equipment.

Our research methodology is based on the statistical analysis of the dependence of the financial results of industrial enterprises on the actual application of the results of intellectual activity to the technological process.

We define the object of analysis by citing research articles and surveys from the WoS database. The patent landscape is assessed using data from commercial information systems such as Orbit Intelligence (Questel) and Amadeus (Bureau van Dijk, Moody's Analytics) that make it possible to visually show the links between patent activity and technological trends in the computer and electronic technology industries.

The research results shall be useful for assessing the effectiveness of employing patents in manufacturing and the prospects of improving production technologies for the formation of corporate innovative technological policy.

We conclude that the use of information on patent trends is an effective tool for increasing the competitiveness of enterprises producing electronic equipment. The priority financing of innovative technologies ensures the sustainable development of the manufacturing industry and have a positive impact on the profitability of enterprise assets.

Keywords: intellectual property, results of intellectual activity, corporate finance, returns on assets, innovative technologies, patent landscape, computer and electronic equipment manufacturing

For citation: Dementev, D. (2021) “How Patents Influence Market Value of Industrial Enterprises' Assets?”, Journal of Corporate Finance Research | ISSN: 2073-0438, 15(3), pp. 70-78. doi: 10.17323/j.jcfr.2073-0438.15.3.2021.70-78. 


\section{Introduction}

Over the past decade (2010-2019), intellectual property rights such as patents, utility models, industrial designs and trademarks have significantly grown in volume. ${ }^{1}$ Why has this occurred? Why have researchers been willing to incur expenses for protecting intellectual innovations? In actual fact, they do so to cast the legal foundations for competitive advantages in different areas of business. Researchers are interested in the trends and development prospects of advanced technology markets and production relations in a wide variety of industrial sectors. There are 6,472 academic papers and surveys relating to intellectual property in the Web of Science Core Collection database for 20162021 (as of August 2021). Approximately 1,220 of them (19\%) deal with legal aspects, 709 (11\%) with management, and $732(11 \%)$ with economics. One way or another, several rapidly developing groups of technologies are considered to be the most advanced and cutting-edge in the world. Science as a productive power spurs the development of big data, robotic technologies, additive manufacturing, the Internet of things (IoT), artificial intelligence, blockchain and other advanced technologies [1-5assessing patent risks has attracted fast-growing attention from both researchers and practitioners in studies of technological innovation. Following the existing literature on risks and intellectual property (IP]. Patent protection issues are thus relevant for both inventors and businessmen.

\section{Data and Methods}

VOSviewer software, a free programme which creates illustrative network interface maps of scientific literature, was applied to analyse publications. VOSviewer can be used to conduct the in-depth analysis [6-8] of texts of research publications and to create slides showing the interrelations of their keywords. The advantage of VOSviewer is that it can be employed to process big bibliographic data sets. It is particularly useful for analysing large numbers of bibliographic objects (over a hundred items) [9-12]. The smart processing of scientific databases normalizes the links between the keywords so as to create maps [12our results showed that a comprehensive bibliometric and visualization investigation was required. The literature on KM has grown rapidly since the 1970s. The United States of America, as the original contributing country, has also internationally collaborated the most in this field of study. The National Cheng Kung University has made the highest number of contributions. The majority of authors contributed a small number of publications. Additionally, the most common category in KM research was management. The main publications for KM research include Journal of Knowledge Management, and Knowledge Management Research \& Practice. A keywords analysis determined that \"knowledge sharingl", ।"innovation \", |"ontologyl", and \"knowledge management $\ "$ were consistent hotspots in knowledge management research. Through a docu- ment co-citation analysis, the intellectual structures of knowledge management were defined, and four emerging trends were identified that focus on new phenomenon, the practice of knowledge management, small and medium enterprises (SMEs] of relations between scientific terms. We processed sets of keywords taken from the Web of Science database. A search using such keywords as Computer Architecture and Network Security identified 1,275 academic papers and surveys for 2016-2021. We also conducted a search using such keywords as Computer Security, Intrusion Detection, Blockchain, and Deep Learning. Moreover, a search in the International Patent Database (WIPO) uncovered 1,842 and 14,095 patents related to computer architecture and network security, respectively. Patent analysis was conducted with the tools of the Questel Orbit patent database, which comprises over 100 sources from world patent collections. The Amadeus database (Bureau van Dijk, Moody's Analytics) was used to define the relation between the number of patents and the financial performance achieved by electronics manufacturers.

\section{Results}

The initial database of 2,208 keywords was compiled by processing bibliographic data from a set of 1,275 documents using the VOSviewer programme. The threshold was then limited to ten occurrences. With these criteria, VOSviewer showed the semantic nodes of 77 keywords (Figure 1). The results of network analysis were grouped into five clusters, which are shown in the figure in different colours. The most important cluster connected the notions of "computer architecture", "Internet of things", and "security".

A natural hypothesis would be that studies mainly focus on the emergence of the global structure of the big data network for artificial devices. In our opinion, artificial intelligence should not be connected too closely with computer-aided learning and security so as not to jeopardize human life. Technological development should be directed at laying the groundwork for sustainable human development, not the development of mechanisms. This shows the importance of such $\mathrm{R} \& \mathrm{D}$ sectors as computer architecture and big data. Scientists have shown that value creation by single enterprises is increasingly rare today due to the growth of industrial cooperation [13]. Bibliometric analysis was used to determine the relation between industrial clusters and global value chains. The creation of industrial conglomerations simultaneously raises the issue of competition and the management of interdependent facilities. In any event, all scientific research results are subjective, and the trustworthiness of their conclusions need to be confirmed by large-scale scientific surveys. On the other hand, big data processing is becoming difficult due to the insufficiency of data storage systems and computing power [14]. 
Figure 1. Keywords network

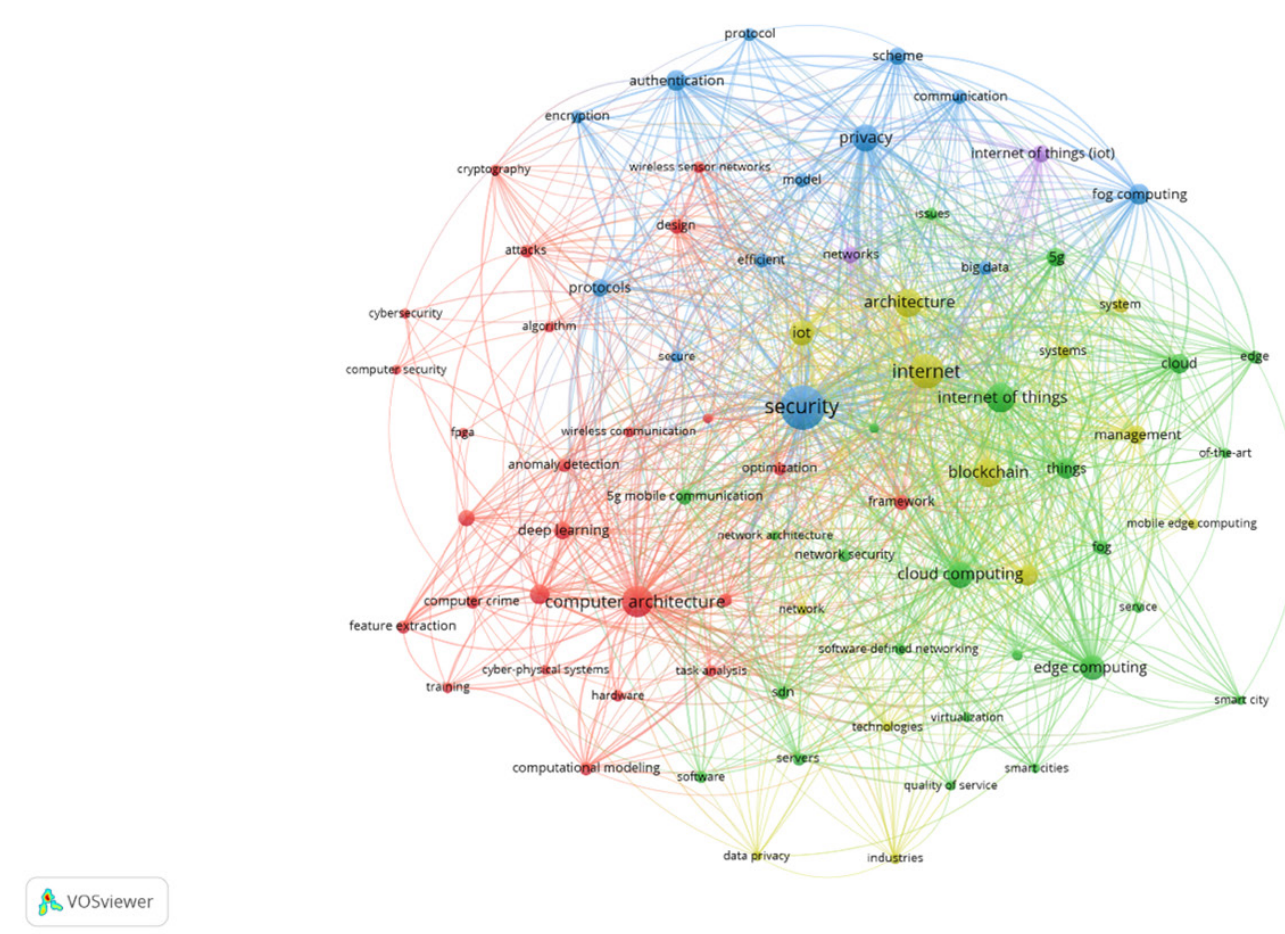

Source: developed by the author using VOSviewer.

A natural hypothesis would be that studies mainly focus on the emergence of the global structure of the big data network for artificial devices. In our opinion, artificial intelligence should not be connected too closely with computer-aided learning and security so as not to jeopardize human life. Technological development should be directed at laying the groundwork for sustainable human development, not the development of mechanisms. This shows the importance of such R\&D sectors as computer architecture and big data. Scientists have shown that value creation by single enterprises is increasingly rare today due to the growth of industrial cooperation [13]. Bibliometric analysis was used to determine the relation between industrial clusters and global value chains. The creation of industrial conglomerations simultaneously raises the issue of competition and the management of interdependent facilities. In any event, all scientific research results are subjective, and the trustworthiness of their conclusions need to be confirmed by large-scale scientific surveys. On the other hand, big data processing is becoming difficult due to the insufficiency of data storage systems and computing power [14]. Nevertheless, as the Internet of things develops, big data processing increases, while scholarly analytics help to evaluate the role of big data in technical processes. Researchers [15] have warned that the growth of the collection of technical network data and a rapid increase in the number of IoT devices can create difficulties for computer networks. To solve this problem, it is necessary to increase the maintenance service capacities for data processing infrastructure. The uninterrupted functioning of computers, cloud storage and data processing systems is very important for manufacturing companies. The factor of data confidentiality is highly significant for the design of computer networks in the IoT domain, as it would otherwise be meaningless to discuss the creation and development of remote-controlled high-tech facilities. Engineers and scientists are focusing their efforts on creating an open reference architecture for big data to provide managers of facilities, programmers, and system engineers with solutions in a compatible big data ecosystem [16]. The general structure of applications for big data integrates weakly connected economic sectors and closely connected corporate data analysis systems and manufacturing control systems. The value of the big data structure for business lies in the fact that available computing and analytical services analyse and visualize data, i.e., help to make more efficient management conclusions for creating value. However, the advantages of network innovations pose serious problems related to security and data reliability [17]. Big data analysis threatens to violate confidentiality at various stages of the life cycle of information units: collection, storage, analysis, use and elimination. Researchers have developed a security taxonomy, which can be used as a methodological guideline for evaluating research results related to the big data life cycle. They also plan to develop a security architecture for the big data life cycle. Adding data mechanically [18] for solving industrial problems does not always yield results. The analysis and interpretation of data are related closely to good database management. Studies [19] have shown that a simple blockchain (Fusion Chain) may improve the security of devices in the Internet of things. Such devices ensure the reliability and integrity of databases without a centralized 
server. Devices for high-speed transactions are also being developed. Another cluster includes algorithms, network intrusion detection systems, machine learning, network security, and modelling. Assuring the stable functioning of industrial databases, the reliable operation of technological equipment, and the error-free detection and counteraction of malicious computer intrusions is of great importance. Scientists [20] have developed tools for the ongoing monitoring of information security for public and private corporations. Timely incident management will assist companies in ensuring information confidentiality in the long term. Artificial intelligence specialists [21] are shifting their attention to heuristic solutions, neural networks, and logical reasoning. For over 60 years, considerable success has been attained in these research areas, yet the field of artificial intelligence looks quite vague at present. This leads to the following key question: what is the role of human knowledge with regard to artificial intelligence? Technology 4.0 serves as a basis for integrating smart machines, manufacturing facilities, physical objects, and people to organise value creation processes at a higher level [22]. The Internet of things, cloud systems, and virtual media are offering new opportunities and posing new threats. Information and data security are of utmost importance for industrial production. Industry 4.0 requires architecture and design security in order to protect smart manufacturing systems. The main problem is that malicious programmes may manipulate technical process data, triggering the production of modified products and changing the duration of the manufacturing cycle. The study [23] assessed the influence of Russian capital markets on investment potential by examining 514 manufacturing companies over the period 2014-2018. The results showed a positive correlation between the cash flows of affiliated companies and investments. These conclusions are of practical importance for large and medium-size companies, which are looking for tools to increase the availability of financial resources in a faltering economy. In particular, a low efficiency of intel- lectual property is observed in the public sector [24] due to its underdeveloped accounting and analysis system. Patent analysis is another method that can be used for intellectual property analysis to solve economic problems. The use of the dynamic innovation theory should clarify the development areas of public enterprises.

Patent activity in the hi-tech sphere is showing impressive dynamics (Figure 2). The number of publications as well as the number of deep learning patents grew approximately tenfold, with blockchain demonstrating the highest growth. Over 2016-2020, the number of patents decreased by $60 \%$ in computer architecture and by $40 \%$ in computer security. An insignificant growth of $15 \%$ occurred in the field of intrusion detection. However, patent activity in network security grew significantly - by $183 \%$. A qualitative increase has been observed in the number of innovative products related to blockchain and deep learning - by almost 13 and 10 times, respectively. On the whole, over 5 years (2016-2020) the increase in the number of academic papers was marked by a strong positive correlation of 0.799 . However, it is always necessary to check the significance of the correlation ratio by applying the zero-hypothesis validation rule. In our calculations, $n=5$ because we analyse statistics over five years:

$$
T=\left|r \sqrt{\frac{n-2}{1-r^{2}}}\right|=\left|0,799 \sqrt{\frac{5-2}{1-0,638}}\right|=2,30 .
$$

The boundary of the criterion $t_{\text {кр }}(\alpha ; k)$ is calculated using Student's $t$-distribution. $t_{\text {кр }}$ is defined by the significance level and depends on the degree of freedom of $k$, which in our case is equal to $n-2$ where $n=5$ (the number of years from 2016 to 2020). It is convenient to calculate the indicator of Student's $t$-distribution by applying the following function: Microsoft Excel T.INV.2T. $(0.01 ; 3)=$ 5.841, i.e. $t_{\text {кр }}=\mathrm{t}_{\text {кр }}(0.01 ; 5-2)=5.841$. As long as $T<t_{\text {кр }}$ the relation is not considered to be significant at a $1 \%$ significance level.

\section{Figure 2. Number of patents}

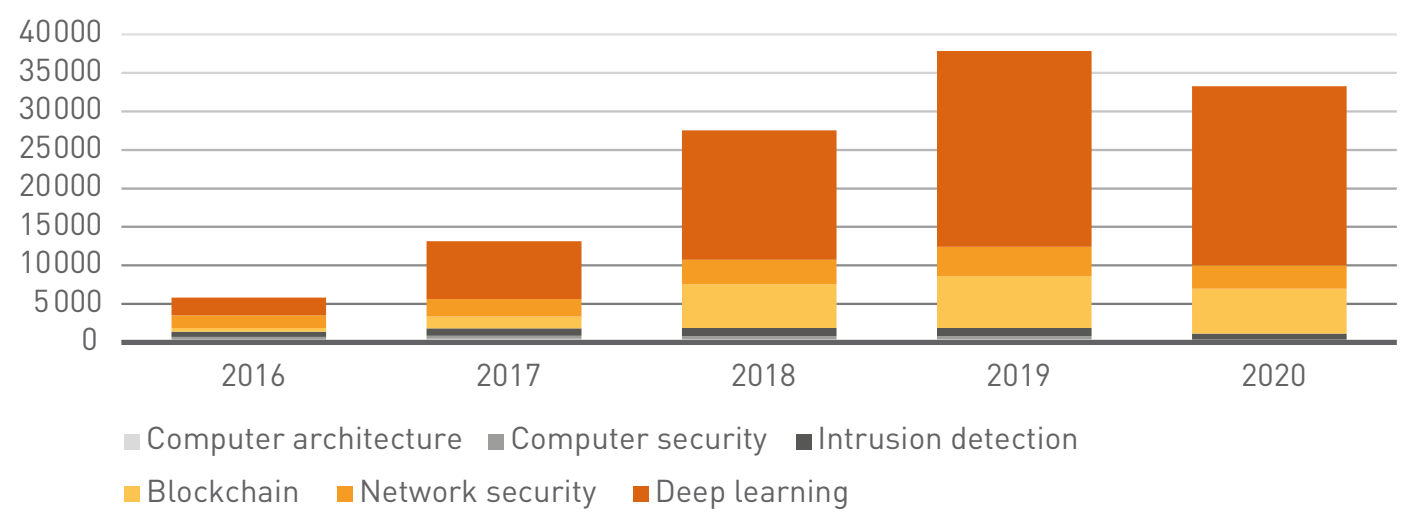

Source: compiled by the author using Orbit Intelligence.

The number of research publications increased for all keywords (Figure 3), albeit the rates of growth were different. Computer architecture grew by 2.5 times, while computer and network security expanded by 224 and 229\%. The interest in intrusion detection increased by a similar factor:
244\%. Blockchain demonstrated an explosive and steady growth, with the number of publications increasing by approximately 66 times. Deep learning publications grew by almost 12 times. 
Figure 3. Number of academic papers and surveys

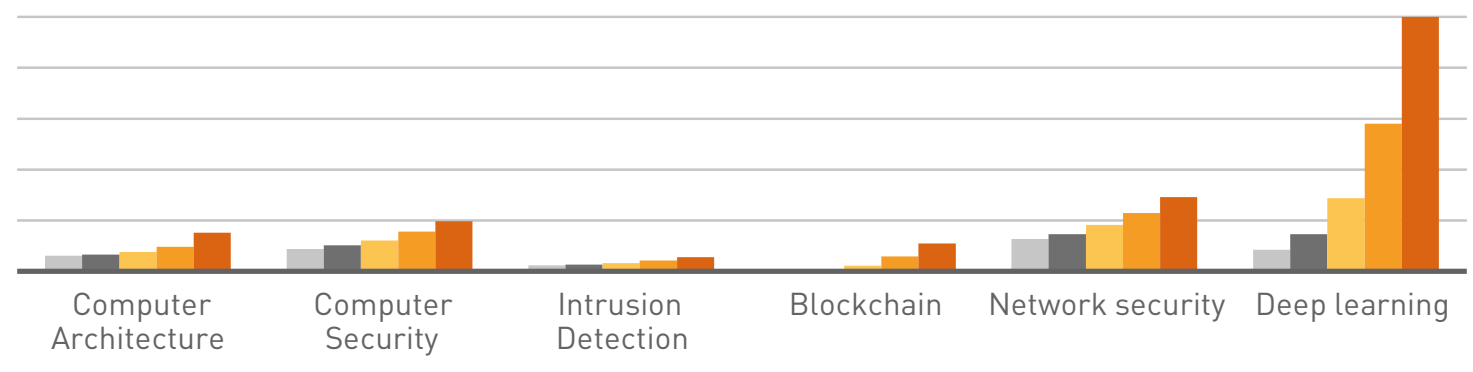

-2016 - $2017-2018-2019-2020$

Source: compiled by the author on the basis of the WoS database.

The correlation between the number of research publications and valid patents is rather ambiguous. Over 20162020, the number of valid patents in the Orbit database and the number of research publications in WoS in the sections Computer Architecture and Computer Security show a strong negative dependence: -0.885 and -0.770 , respectively. How objectively do these figures reflect the correlation between intellectual property rights and research publications? Usually the zero-hypothesis verification rule is used to verify the significance of the correlation ratio. In our calculations $n=5$, because we analysed statistics over five years and more:

$$
T=\left|r \sqrt{\frac{n-2}{1-r^{2}}}\right|=\left|0,885 \sqrt{\frac{5-2}{1-0,783}}\right|=3,29 \text {. }
$$

The boundary of the criterion $t_{\mathrm{kp}}(\alpha ; k)$ was calculated on the basis of Student's $t$-distribution. $t_{\mathrm{kp}}$ is defined by the significance level and depends on the degree of freedom of $k$, which in our case is equal to $n-2$, where $n=5$ (number of years from 2016 to 2020). It is easy to calculate the value of $t_{\text {кр }}$ by applying the function: Microsoft Excel T.INV.2T. $(0.01 ; 3)=5.841$, which corresponds to $t_{\mathrm{\kappa p}}=t_{\mathrm{kp}}(0.01 ; 5-2)$ $=5.841$. We have $T<t_{\text {кр }}$; therefore, the relation cannot be objectively considered to be significant at a $1 \%$ significance level.

In the field of Intrusion Detection, the number of patents virtually does not depend on the number of research publications (correlation ratio of 0.083 ). For the field of Blockchain, we calculate significance using the following formula:

$$
T=\left|r \sqrt{\frac{n-2}{1-r^{2}}}\right|=\left|0,083 \sqrt{\frac{5-2}{1-0,007}}\right|=0,14 .
$$

$0.14<5.841$, and so the relation cannot be considered significant at a $1 \%$ significance level. Similarly, the correlation between the number of Network Security patents (0.713) and the number of studies dedicated to this topic seems to be indicative of a strong express positive relation at first sight. We make the following simple calculations in order to prove this hypothesis:

$$
T=\left|r \sqrt{\frac{n-2}{1-r^{2}}}\right|=\left|0,713 \sqrt{\frac{5-2}{1-0,508}}\right|=1,76,
$$

and for Deep Learning with the ratio of 0.704 :

$$
T=\left|r \sqrt{\frac{n-2}{1-r^{2}}}\right|=\left|0,704 \sqrt{\frac{5-2}{1-0,496}}\right|=1,72 .
$$

The values of the random variable $T$ are significantly less than the critical value of Student's criterion in both cases, and so the correlation indicator cannot be considered significant. A longer period of analysis may be necessary - much longer than five years.

Researchers naturally take an interest in the influence of intellectual property on corporate financial performance. However, it is impossible to assess here the whole range of research work and the scope of implementation of innovative technologies. The economy must be stable in the long term, and the global survey Digital Trust by the audit and business consulting firm $\mathrm{PWC}^{2}$ suggests some general conclusions. Information security is ensured by means of innovative cryptography, a technology which has been preventing hacker attacks for almost 40 years (the Massachusetts Institute of Technology in the USA obtained a patent for cryptographic protection in 1983). The PWC survey is based on a 2020 poll of 3,249 company directors who were actually engaging in business digitalization. The COVID-19 pandemic necessitated automatization to cut costs (47\% in Russia, 35\% in the world). $26 \%$ of Russian companies and $37 \%$ of companies across the globe consider the quality of information to be the \#1 concern. Breakthrough technologies using zero-trust architecture to analyse risks online allow the introduction of preliminary protective measures to prevent criminals from committing unlawful acts. Investments in technology lead to reduced operating costs. The PWC survey speaks of 25 innovative approaches in the sphere of information security - for example, the quality of risk management has improved greatly (approximately by $76 \%$ ) along with confidence in digital technologies (by $81 \%$ in Russia and by $76 \%$ in the world). 
Table 1. Dynamics of the return on assets of electronic equipment element manufacturers and the number of valid patents

\begin{tabular}{|c|c|c|c|c|c|}
\hline $\begin{array}{l}\text { OKVED (Russian National Classifier of } \\
\text { Types of Economic Activity) } 26.11\end{array}$ & 2016 & 2017 & 2018 & 2019 & 2020 \\
\hline Return on assets ${ }^{*}$ & 7.59 & 6.90 & 6.49 & 9.99 & 10.87 \\
\hline Number of patents & 397 & 57 & 341 & 16.279 & 4.305 \\
\hline
\end{tabular}

${ }^{*}$ On the basis of net profit.

Source: database: URL: https://amadeus.bvdinfo.com

Table 2. Dynamics of return on assets of manufacturers of electronic printed circuit boards and of the number of valid patents

\begin{tabular}{lcccccc}
$\begin{array}{l}\text { OKVED (Russian National Classifier of } \\
\text { Types of Economic Activity) 26.12 }\end{array}$ & 2016 & 2017 & 2018 & 2019 & 2020 \\
$\begin{array}{l}\text { Return on assets } \\
*\end{array}$ & $* *$ & $* *$ & 6.64 & 6.57 & 12.33 \\
\hline Number of patents & $* *$ & $*$ & $*$ & 24 & 821 & 52 \\
\hline
\end{tabular}

* On the basis of net profit

** No data available.

Source: database. URL: https://amadeus.bvdinfo.com

This has led to a staff shortage in the sphere of cloud services and the analysis of security factors. It has been estimated that there will be approximately 3.5 million "digital" vacancies in the world in 2021. The PWC survey polled directors in Western Europe (34\%), North America (29\%), Asia (18\%), Latin America (8\%), Eastern Europe (4\%), the Middle East (3\%) and Africa (3\%).

The DIGITAL IQ in Russia 2020 joint study ${ }^{3}$ by PWC and ABBYY (February 2021) surveyed 106 top managers of large Russian companies in the following sectors: information technology (19\%), industry (14\%), telecommunications, financial sector, transport, education (approximately $7 \%$ each), marketing, services for businesses, construction (approximately 6\% each) and other types of economic activity (20\%). It conjectured that the digital intelligence strategy is shaped by three factors: employees' digital mindset, software infrastructure and available innovations. Today, digitalization (the improvement of technology and management processes) is playing a significant role in Russian business. The most relevant advanced technologies are artificial intelligence, the Internet of things and robots. Ideally, advanced technologies should be used systemically at enterprises (according to about $81 \%$ of managers) and, at the same time, should work harmoniously together (according to $74 \%$ of managers). Due to the demand for real-time technical process analysis, the highest growth $(140 \%)$ is forecast for Process Mining. Naturally, advanced technology shall be used to increase labour productivity (by $74 \%$ ) and cut costs (by 58\%). Artificial intelligence should show a growth of $76 \%$ over the two coming years. In 2019, CRI Electronics (an analytic centre of the radio-electronic industry) compiled a rating 4 of 69 radio-electronic enterprises with a total revenue of RUB 150 billion and approximately 62.5 thousand employees. Industrial goods accounted for about $64 \%$ of the revenue, and R\&D for approximately $24 \%$. JSC RPC Istok had the greatest income of RUB 12.3 billion, the Mikron Group came in second with RUB 11.7 billion, while the Research Institute of Communication and Control Systems was third with RUB 8.5 billion. The majority of enterprises invest little into new technologies at their own initiative - about only $5 \%$ of their revenues, which hinders the introduction of successful competitive products.

Let us now turn to the patent analysis of the computer industry. From the Amadeus database (August 2021), we obtained the financial indicators and number of patents in several advanced industries, including 26.11 (2017 OKVED (Russian National Classifier of Types of Economic Activity)) - production of electronic device parts, 26.12 production of electronic printed circuit boards, 26.20 production of computers and peripheral equipment, and 26.70 - production of optical equipment. The study period was the five years from 2016 to 2020 . Table 1 presents the data of 118 profitable sectoral enterprises (with a positive return on assets).

The correlation between the return on assets and the number of patents is definitely positive, amounting to 0.669 .

\footnotetext{
${ }^{3}$ Research by PwC and ABBYY. URL: https://www.abbyy.com/ru

${ }^{4}$ Analytical materials of CRI Electronics. URL: https://www.instel.ru
} 
Does this figure reliably measure the correlation between intellectual property rights and corporate financial performance? We can use the zero-hypothesis verification rule to check the significance of the correlation ratio. In our calculations $n=5$, because we analysed statistics over five years.

$$
T=\left|r \sqrt{\frac{n-2}{1-r^{2}}}\right|=\left|0,669 \sqrt{\frac{5-2}{1-0,552}}\right|=1,56 .
$$

The boundary of the criterion $t_{\text {кр }}(\alpha ; k)$ was calculated using Student's $t$-distribution. $t_{\text {кр }}$ is defined by the significance level and depends on the degree of freedom of $k$, which in our case is equal to $n-2$, where $n=5$ (number of years from 2016 to 2020). We calculate the value of the indicator by applying the function: Microsoft Excel T.INV.2T. (0.01; $3)=5.841$. As we have $T<t_{\text {кр }}(1.56<5.84)$, the relation cannot be considered significant at a $1 \%$ significance level. Probably, the analysis period needs to be significantly longer than five years. Unfortunately, the Amadeus database lacks the required data in this case. For the purposes of comparison, let us take a look at the analogous indicators of other groups of electronics and optics manufacturers. While the database comprises 132 enterprises manu-

facturing electronic printed circuit boards (26.12), Table 2 presents only 21 profitable companies.

Using Table 2, Excel calculations for three years show a negative correlation of -0.482 , i.e., if $n=3$, the random variable is equal to

$$
T=\left|r \sqrt{\frac{n-2}{1-r^{2}}}\right|=\left|0,482 \sqrt{\frac{3-2}{1-0,232}}\right|=0,55 \text {. }
$$

In this case, calculations using Microsoft Excel T.INV.2T. $(0.01 ; 1)$ show that $\mathrm{T}=63.657$ and $T<t_{\text {кр }}(0.55<63.657)$, and so the relation cannot be considered significant at a $1 \%$ significance level. We repeat that larger data sets are needed to calculate the significance of the statistical correlation between factors and results. Table 3 presents the indicators of computer manufacturers: 41 profitable enterprises out of 308 (Amadeus database). In this sector, the correlation between patents and the return on assets is positive and quite strong: 0.622. Therefore, for small samples the following is true: if $n=4$,

$$
T=\left|r \sqrt{\frac{n-2}{1-r^{2}}}\right|=\left|0,622 \sqrt{\frac{4-2}{1-0,387}}\right|=1,12 .
$$

\begin{tabular}{|c|c|c|c|c|c|}
\hline $\begin{array}{l}\text { OKVED (Russian National Classifier of } \\
\text { Types of Economic Activity) } 26.20\end{array}$ & 2016 & 2017 & 2018 & 2019 & 2020 \\
\hline Return on assets ${ }^{\star}$ & $* *$ & 3.96 & 12.47 & 8.54 & 13.99 \\
\hline Number of patents & $* *$ & 13 & 82 & 1,412 & 4,459 \\
\hline
\end{tabular}

Table 3. Dynamics of the return on assets of computer manufacturers and of the number of valid patents

* On the basis of net profit

** No data available.

Source: database: URL: https://amadeus.bvdinfo.com

The calculations show $T<t_{\text {кp }}(1.12<63.657)$, and so the relation cannot be considered significant at a $1 \%$ significance level. Table 4 represents profitable enterprises manufacturing optical equipment (111 out of 274) and the number of valid

\begin{tabular}{|c|c|c|c|c|c|}
\hline $\begin{array}{l}\text { OKVED (Russian National Classifier of } \\
\text { Types of Economic Activity) } 26.70\end{array}$ & 2016 & 2017 & 2018 & 2019 & 2020 \\
\hline Return on assets * & 8.01 & ** & 3.14 & 9.77 & 10.22 \\
\hline Number of patents & 2 & ** & 4 & 69 & 111 \\
\hline
\end{tabular}
patents in their assets.

Table 4. Dynamics of the return on assets of optical equipment manufacturers and of the number of valid patents

* On the basis of net profit.

** No data available.

Source: database: URL: https://amadeus.bvdinfo.com 
The correlation over the period of $2018-2020$ is close to 1 : 0.942. So, calculations yield the following result:

$$
T=\left|r \sqrt{\frac{n-2}{1-r^{2}}}\right|=\left|0,942 \sqrt{\frac{3-2}{1-0,936}}\right|=3,66 \text {. }
$$

We have $T<t_{\text {кр }}(3.66<63.657)$, and so the relation cannot be considered significant at a $1 \%$ significance level.

\section{Conclusion}

In 2016-2020, patents and academic papers were closely connected with each other, as shown by the positive correlation ratio of 0.799 . On the one hand, intellectual property exerts some influence on corporate financial performance as well as promoting the dynamic development of the innovation technological paradigm in the Russian economy. On the other, an increasing number of patents requires improving the actual legal protection of intellectual results to make the expenditures on developing intellectual property reasonable and economically viable.

Of the academic papers and surveys dealing with the topic of Intellectual Property in the Web of Science Core Collection in recent years (2016-2021), 11\% were dedicated to economics and another $11 \%$ to management problems. Our analysis of patent landscapes and research publications related to computer technologies generated five clusters of keywords connected with the terms Computer Architecture and Network Security. The number of publications and the number of patents related to Deep Learning and Blockchain increased by an order of magnitude.

Over 2016-2020, research publications and valid patents relating to Computer and Network Security, Blockchain, Deep Learning, and Intrusion Detection showed a strong positive correlation of 0.799 . However, the calculated values of $T$ and $t_{\mathrm{rp}}$ show that the correlation cannot be considered significant at a $1 \%$ significance level. In the opinion of the directors of Russian companies working in the area of information technology, the most relevant and prospective technologies are artificial intelligence, the Internet of things, and robots. However, according to 2019 data, 69 Russian radio-electronic enterprises invested no more than $5 \%$ of their net profits in R\&D.

According to Amadeus data on electronics manufacturers in 2016-2020, the net profit margin and the number of valid patents of enterprises showed a correlation of 0.669 . Firms manufacturing electronic printed circuit boards had a negative correlation of -0.482 . In this case, data for calculations was available only for 2018-2020. There is a positive dependence of 0.662 among computer manufacturers. The highest correlations between profitability and the number of patents (0.942) were found among enterprises manufacturing optical equipment. The significance of the correlation has been calculated for all industry sectors: the obtained values of $T$ and $t_{\text {кр }}$ show that the correlation cannot be considered significant at a $1 \%$ significance level. The results of the present study are both qualitative and quantitative in nature. The qualitative results show the expediency of the systemic use of innovative equipment, materials and technologies in manufacturing. The quantitative results provide calculations of the impact of innovative machines, mechanisms, materials, and technologies (created on the basis of patents) on the actual production of high-tech products that are in demand today.

\section{References}

1. Hu D, Liu Z, Zhao J. Will Intellectual Property Rights Policy Increase Foreign Direct Investment and Promote Technological Innovation? Mathematical Problems in Engineering. 2021 Jan 27;2021:1-11.

2. Krauß J, Kuttenkeuler D. When to file for a patent? The scientist's perspective. New Biotechnology. 2021 Jan 25;60:124-9.

3. Hu Y, Hou Y (Greg), Oxley L, Corbet S. Does blockchain patent-development influence Bitcoin risk? Journal of International Financial Markets, Institutions and Money. 2021 Jan 1;70.

4. Miyashita S, Katoh S, Anzai T, Sengoku S. Intellectual property management in publicly funded $r \& d$ program and projects: Optimizing principal-agent relationship through transdisciplinary approach. Sustainability (Switzerland). 2020 Dec 1;12(23):1-17.

5. Yang X, Yu X. Preventing patent risks in artificial intelligence industry for sustainable development: A multi-level network analysis. Sustainability (Switzerland). 2020 Oct 2;12(20):1-22.

6. Li B, Xu Z, Zavadskas EK, Antuchevičiene J, Turskis Z. A bibliometric analysis of symmetry (2009-2019). Symmetry. 2020;12(8).

7. Zhou W, Xu Z, Zavadskas EK. A bibliometric overview of the international journal of strategic property management between 2008 and 2019. International Journal of Strategic Property Management. 2019;23(6):366-77.

8. Wang X, Xu Z, Škare M. A bibliometric analysis of Economic Research-Ekonomska Istraživanja (20072019). Economic Research-Ekonomska Istrazivanja. 2020 Jan 1;33(1):865-86.

9. Cañas RM, Caruso NM, González-Torres T, Rodríguez-Sánchez J-L, Montero-Navarro A, Es AM, et al. Visualizing Research on Industrial Clusters and Global Value Chains: A Bibliometric Analysis. A Bibliometric Analysis Front Psychol [Internet]. 2020;11:1754. Available from: www. frontiersin.org

10. Huang Y, Ding X-H, Liu R, He Y, Wu S. Reviewing the Domain of Technology and Innovation Management: A Visualizing Bibliometric Analysis. SAGE OPEN [Internet]. 2019;9(2). Available from: https://doi.org/10.1177/2158244019854644 
11. Nakagawa S, Samarasinghe G, Haddaway NR, Westgate MJ, O’Dea RE, Noble DWA, et al. Research Weaving: Visualizing the Future of Research Synthesis. TRENDS IN ECOLOGY \& EVOLUTION. 2019;34(3):224-38.

12. Wang P, Zhu FW, Song HY, Hou JH, Zhang JL. Visualizing the academic discipline of knowledge management. Sustainability (Switzerland). 2018;10(3).

13. Yu D, Xu Z, Pedrycz W, Wang W, Cañas RM, Caruso $\mathrm{NM}$, et al. Visualizing Research on Industrial Clusters and Global Value Chains: A Bibliometric Analysis. A Bibliometric Analysis Front Psychol [Internet]. 2019 Dec 1 [cited 2021 Mar 26];11(2):1754. Available from: https://doi.org/10.1177/2158244019854644

14. Liao X, Faisal M, Qing Chang Q, Ali A. Evaluating the Role of Big Data in IIOT-Industrial Internet of Things for Executing Ranks Using the Analytic Network Process Approach. Scientific Programming. 2020;.

15. Dubuc T, Stahl F, Roesch EB. Mapping the Big Data Landscape: Technologies, Platforms and Paradigms for Real-Time Analytics of Data Streams. IEEE Access. 2021;9:15351-74.

16. Mathrani S, Lai X. Big Data Analytic Framework for Organizational Leverage. 2021; Available from: https://doi.org/10.3390/app11052340

17. Koo J, Kang G, Kim Y-G. sustainability Security and Privacy in Big Data Life Cycle: A Survey and Open Challenges. Available from: www.mdpi.com/journal/ sustainability
18. Brous P, Janssen M. Trusted Decision-Making: Data Governance for Creating Trust in Data Science Decision Outcomes. Administrative Sciences. 2020;10(4):81.

19. Na D, Park S. Fusion chain: A decentralized lightweight blockchain for iot security and privacy. Electronics (Switzerland). 2021;10(4):1-18.

20. Kiss M, Breda G, Muha L. Information security aspects of Industry 4.0. In: Procedia Manufacturing. Elsevier B.V.; 2019. p. 848-55.

21. Brock DC. Learning from artificial intelligence's previous awakenings: The history of expert systems. AI Magazine. 2018;39(3):3-15.

22. Alcácer V, Cruz-Machado V. Scanning the Industry 4.0: A Literature Review on Technologies for Manufacturing Systems. Vol. 22, Engineering Science and Technology, an International Journal. Elsevier B.V.; 2019. p. 899-919.

23. Korotkova YI. Internal capital markets in russian business groups: evidence from corporate investments. Journal of Corporate Finance Research. 2020;14(2):58-71.

24. Khomenko E V. Review of methods and tools for intellectual property analysis of public sector entities. Journal of Corporate Finance Research. 2020;14(3):6389.

Contribution of the authors: the authors contributed equally to this article.

The authors declare no conflicts of interests.

The article was submitted 06.08.2021; approved after reviewing 08.09.2021; accepted for publication 14.09.2021. 